\title{
Numerical Investigation on the Mechanism of Rock Directional Fracturing Method Controlled by Hydraulic Fracturing in Dense Linear Multiholes
}

\author{
Qingying Cheng $\mathbb{D}^{1},{ }^{1}$ Bingxiang Huang $\mathbb{D},{ }^{2}$ and Xinglong Zhao $\mathbb{D}^{2}$ \\ ${ }^{1}$ Jiangsu Key Laboratory of Fire Safety in Urban Underground Space, China University of Mining and Technology, Xuzhou, \\ Jiangsu 221116, China \\ ${ }^{2}$ State Key Laboratory of Coal Resources and Safe Mining, China University of Mining and Technology, Xuzhou, \\ Jiangsu 221116, China
}

Correspondence should be addressed to Bingxiang Huang; huangbingxiang@cumt.edu.cn

Received 8 October 2020; Revised 6 November 2020; Accepted 11 November 2020; Published 25 November 2020

Academic Editor: Junfei Zhang

Copyright (c) 2020 Qingying Cheng et al. This is an open access article distributed under the Creative Commons Attribution License, which permits unrestricted use, distribution, and reproduction in any medium, provided the original work is properly cited.

\begin{abstract}
Rock directional fracturing is one of the difficult problems in deep mines. Directional fracturing controlled by hydraulic fracturing in dense linear multiboreholes is a novel directional fracturing technology of rock mass, which has been applied to the ground control in mines. In this paper, a physical model experiment was performed to study the fracture propagation process between multiboreholes. The results show that the intersecting of fractures between boreholes caused the sharp fluctuation of injecting water pressure. A directional fracturing plane was formed along with the direction of boreholes layout, and the surface of the fracturing plane is relatively flat. The dynamic initiation and propagation process of cracks between boreholes during directional hydraulic fracturing were simulated. The evolution of poroelastic stress and pore pressure between multiboreholes was analyzed. The numerical results indicated that a poroelastic stress concentration zone and pore pressure increase zone appeared between boreholes in the direction of boreholes layout. The pore pressure distribution is generally an elliptical seepage water pressure zone with the long axis along the direction of the boreholes layout. After the hydraulic fractures are initiated along the direction of the boreholes layout, the poroelastic stress on both sides of fractures decreases.
\end{abstract}

\section{Introduction}

Directional fracturing is a common and significant problem in rock engineering [1-3]. Directional hydraulic fracturing is an effective directional fracturing technology, which has been widely applied in oil and gas engineering and mining engineering, such as hydraulic fracturing with oriented perforation and preslotting directional hydraulic fracturing [4-7]. The oriented perforation is a key technology in reservoir stimulation of oil and gas wells, which can control the initiation direction of fractures in near-wellbore [8-13].

At present, preslotting directional hydraulic fracturing technology includes two types according to the slotting method. One is the mechanical slotting method, and another one is the hydraulic slotting method. The mechanical preslotting directional hydraulic fracturing is achieved by using a mechanical device to produce a wedge ring slot at the bottom of the borehole, which induced the borehole to initially fractured along the wedge ring slot direction due to the stress concentration [14-18]. The hydraulic method for preslotting directional hydraulic fracturing is achieved by pre-water jet slotting to produce a fracturing plane along the radial or axial of the borehole. A stress concentration will appear at the tip of the fracturing plane, which caused the borehole to initiate along the desired direction during the subsequent hydraulic fracturing [19-21].

However, these current directional hydraulic fracturing technologies only focus on controlling the directional initiation of hydraulic fractures by taking some directional measure to ensure the fracture initiation along the desired 
direction. The subsequent directional propagation is indirectly controlled through directional initiation. The related research indicated that when the perforation or preslotting is not perpendicular to the direction of the minimum principal in situ stress, the initiation direction of hydraulic fracture will be first along the direction of the perforation or preslotting direction, but the final propagation direction of hydraulic fracture will gradually turn to be perpendicular to the direction of the minimum principal in situ stress [22]. The hydraulic fracture reorientation took place within 2.2-5.8 wellbore diameters. Therefore, the effective range of orientation is very limited [10].

This study focuses on a rock directional fracturing method controlled by hydraulic fracturing in dense linear multiholes (Figure 1) [23, 24]. This method considered the superimposing and coupling of poroelastic stress and pore pressure between the dense linear boreholes to produce a stress concentration area. Both the initiation and propagation of hydraulic fractures were controlled to be along the direction of boreholes layout, which can form a better directional fracturing plane. In the process of directional fracturing of the hard roof in underground coal mines, rapid drilling construction can be carried out with anchor rigs. The spacing of dense boreholes can be $0.5-1 \mathrm{~m}$, and the number of boreholes in a group can be $5-10$ to perform the controlling directional hydraulic fracturing. Directional fracturing controlled by hydraulic fracturing in dense linear multi-boreholes is a novel directional fracturing technology of rock mass, which has been applied to the ground control in mines. It also can be applied to the directional fracturing and excavation of rock in underground geotechnical engineering, tunnel engineering, and directional excavation of slope engineering. As long as the rock is hard and has good integrity, this technology can be applied.

In this paper, a physical model experiment was performed to study the fracture propagation process between multiboreholes. The dynamic initiation and propagation process of cracks between multiboreholes during directional hydraulic fracturing was simulated. The evolution of poroelastic stress and pore pressure between multiboreholes was analyzed.

\section{Physical Model Experiment}

2.1. Experimental Design. A true triaxial hydraulic fracturing experimental system was used in this study (Figure 2), and a cubic cement mortar sample with a size of $500 \times 500 \times 500 \mathrm{~mm}^{3}$ was used to simulate the coal rock mass (Figure 3). The physical and mechanical properties of the sample are shown in Table 1.

A three-dimensional stress field with $\sigma_{1}=6 \mathrm{MPa}$, $\sigma_{2}=5 \mathrm{MPa}$, and $\sigma_{3}=4 \mathrm{MPa}$ was loaded to the sample to simulate the in situ stress. During the experiment, one channel was used to inject high-pressure water into the three boreholes with a pumping rate of $600 \mathrm{~mL} / \mathrm{min}$. The pumping pressure is equal in each borehole.
2.2. Experiment Results and Analysis. The water pressure curve during hydraulic fracturing is shown in Figure 4, which can be divided into five parts: the rise of water-injection pressure $(\mathrm{AB})$, cracks initiation $(\mathrm{BC})$, cracks independent propagation (CD), cracks intersecting and overall propagation (DE), and pressure release due to the hydraulic fracture propagating to the sample surface (EF), respectively.

In the first $100 \mathrm{~s}$, the water output from the pump is used to fill the pipeline and boreholes, after which the water pressure rises rapidly $(\mathrm{AB})$. At $173 \mathrm{~s}$, the water pressure rose to the maximum value of $9.62 \mathrm{MPa}$ and crack initiation occurs. After crack initiation, the effective volume used for filling the initial hydraulic cracks decreases, which leads to the water pressure decreased slightly by $21.04 \%$ (BC). After that, the hydraulic fracture propagates independently, and the water pressure is stable at around $8.3 \mathrm{MPa}(\mathrm{CD})$. At $370 \mathrm{~s}$, the hydraulic fractures of the three boreholes intersect and connect with each other, and the water pressure curve decreased sharply, with a drop of $38.43 \%$. Subsequently, the hydraulic fracture propagates overall. The water pressure rises again to the second peak and then falls again. It continuously fluctuates within the range of 4-6 MPa (DE). The pumping stopped when the hydraulic fracture propagates through the surface of the sample. The water pressure drops rapidly and then gradually decreases '(EF).

After the experiment, the sample was taken out from the experimental frame. The morphology of the hydraulic fracture was shown in Figure 5. A directional fracturing plane was formed along the direction of the boreholes layout, and the surface of the fracturing plane is relatively flat. All three boreholes were fractured, the cracks propagated towards each other between holes finally intersected and connected.

The poroelastic stress concentration zone and pore pressure increase zone occurred between the holes after injecting water simultaneously into the multiholes. It created a maximal effective tensile stress at the direction of boreholes layout, which priority to exceed the fracturing strength of the sample. Therefore, the fractures initiated along the direction of boreholes layout due to the superimposing of poroelastic stress and pore pressure, and hydraulic-mechanics coupling effect between boreholes. Because the fractures propagation area was still located at the superimposing area of poroelastic stress and pore pressure, the fractures did not alter the extending direction. They continue to propagate along the initiation direction and extend toward each other between boreholes. A wide range of ruptures occurred when the cracks tip intersects and connect each other, which caused a sharp water pressure relief. After that, a connected water pressure area was formed. The hydraulic fractures continued to extend as an overall fracturing plane until it extended to the surface of the sample. The initiation and propagation direction of the hydraulic fractures in each hole is consistent and all along the direction of boreholes layout, which is the guarantee for forming a single flat directional fracturing plane. 


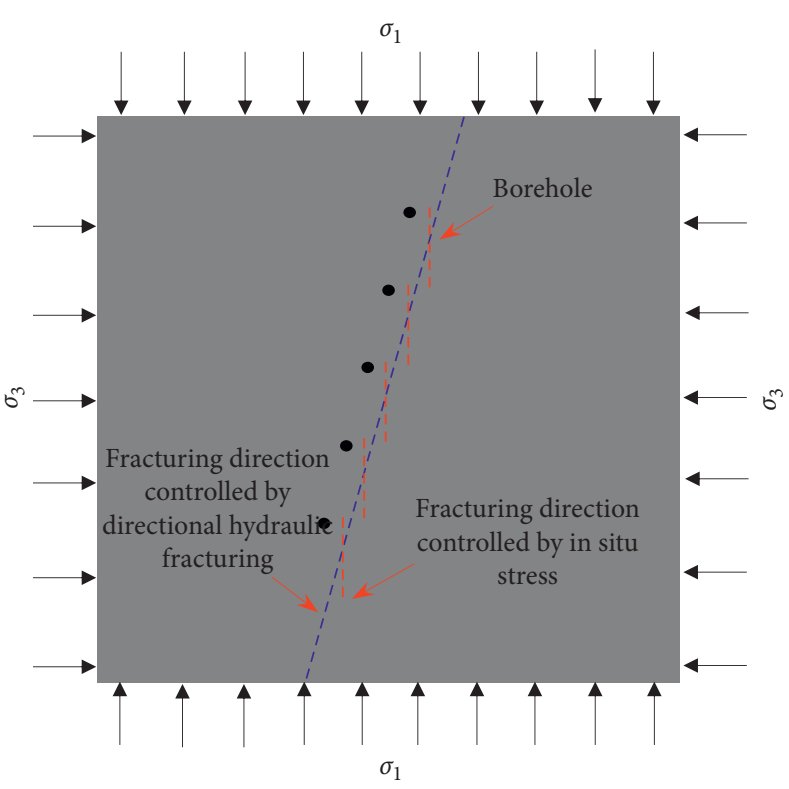

(a)

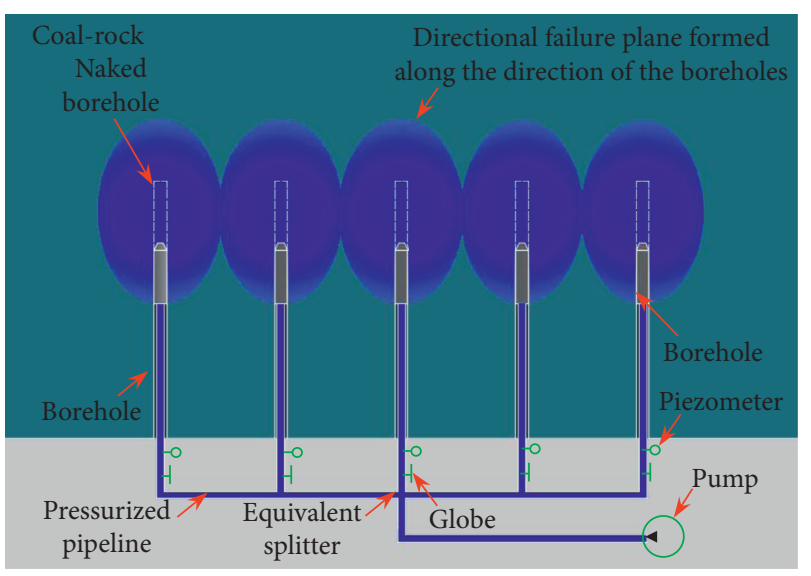

(b)

Figure 1: The technical principle and process of directional hydraulic fracturing controlled by dense linear multi-boreholes. (a) Vertical view. (b) Horizontal view [23].

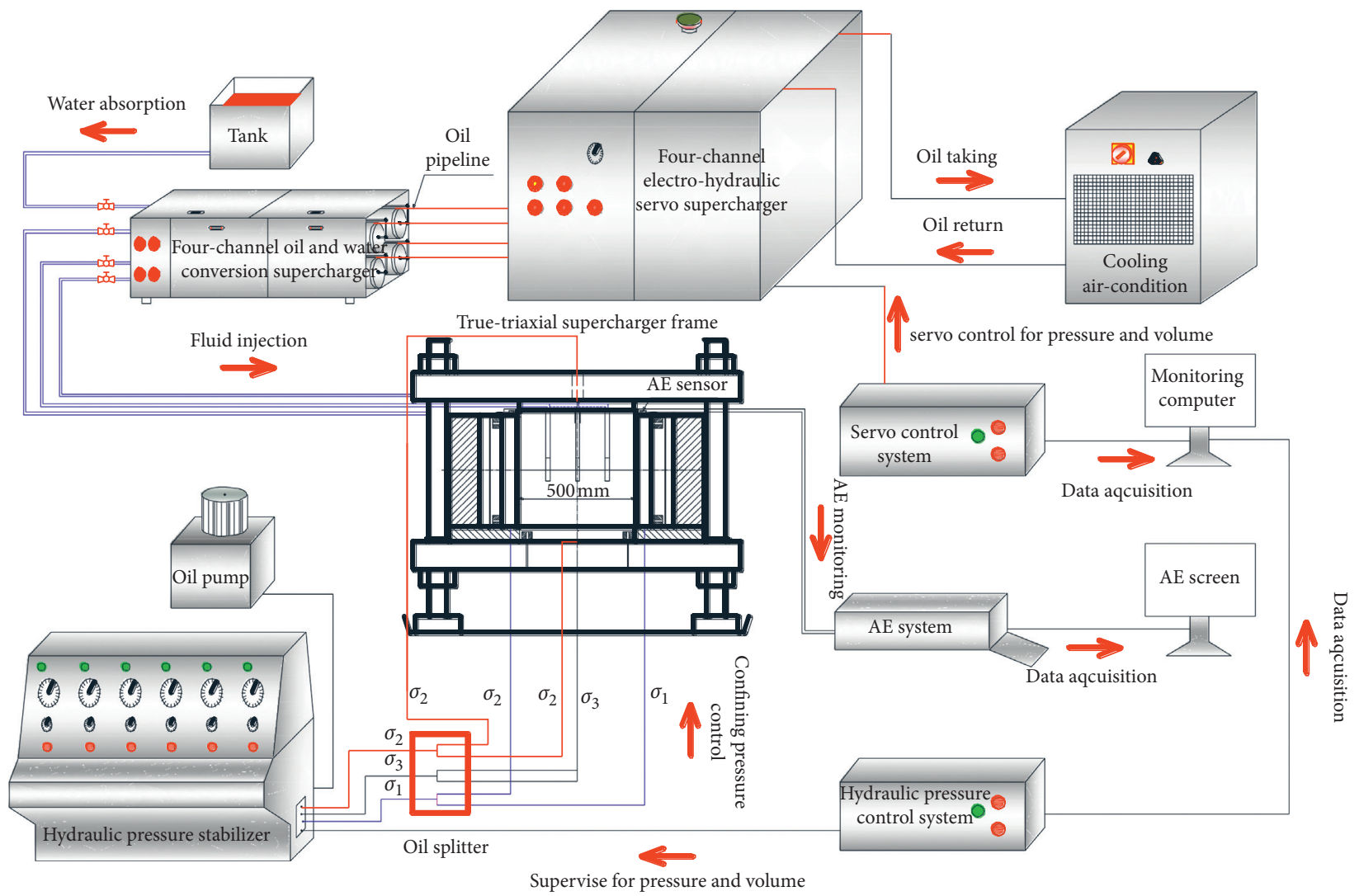

Figure 2: Experimental system for true triaxial hydraulic fracturing [23]. 


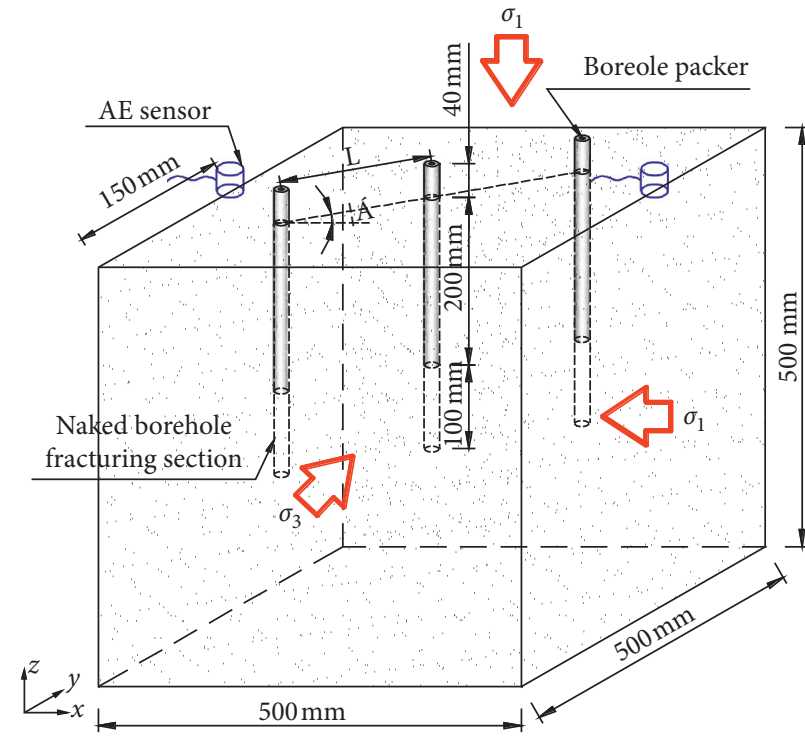

(a)

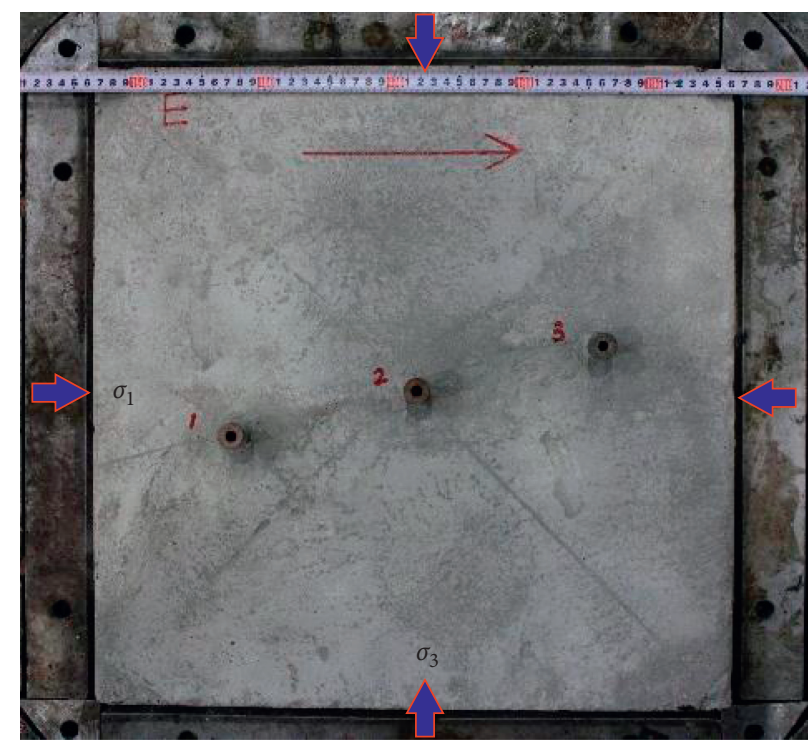

(b)

Figure 3: The cement mortar test block. (a) Size structure and loading schematic diagram [23]. (b) Test block placed in the pressurized frame.

\section{Numerical Simulation Model Using RFPA2D- Flow}

3.1. Background of RFPA2D-Flow. The Coupled Analysis of Flow and Solid Mechanics in Rock Failure Process Analysis software RFPA2D-Flow was developed by Dalian Mechanics Software Co., Ltd. (China) [25-27]. This is a numerical test software that can simulate the progressive failure of a quasibrittle material. The calculation method is based on finite element theory and statistical damage theory. This method takes into account the non-uniformity of material properties and the random distribution of defects [25].

The formulation of seepage-stress coupling is based on the following basic assumptions, which are described in detail elsewhere [26, 28, 29]:

(1) The seepage process of rock mass satisfies Biot's consolidation theory and the modified Terzaghi effective stress principle.

(2) The rock mass is fully saturated and is a brittle elastic material with residual strength. Besides, its loading and unloading behaviours are following the elastic damage mechanics.

(3) Regard the maximum tensile strength criterion and the Mohr-Coulomb failure envelope as the damage threshold condition of element.

(4) Variation in the permeability of rock as a function of the stress states in elastic deformation. The variation increases dramatically when the element fails.

(5) The local heterogeneity in the properties of rock masses is defined by the Weibull function, which is given as follows:
TABLE 1: Physical and mechanical parameters of the cement mortar.

\begin{tabular}{lc}
\hline Properties $($ Unit $)$ & Value \\
\hline Porosity $(\phi / \%)$ & 12.7885 \\
Permeability $(K / \mathrm{mD})$ & 1.1339 \\
Uniaxial compressive strength $\left(\sigma_{c} / \mathrm{MPa}\right)$ & 6.2747 \\
Elastic modulus $(E / \mathrm{MPa})$ & 0.7208 \\
Tensile strength $\left(\sigma_{t} / \mathrm{MPa}\right)$ & 1.6487 \\
Cohesion $(c / \mathrm{MPa})$ & 2.5443 \\
Internal friction angle $\left(\varphi /{ }^{0}\right)$ & 31.2900 \\
Fracture toughness $\left(K_{1 c} / \mathrm{N} \cdot \mathrm{mm}^{(3 / 2)}\right)$ & 13.2300 \\
\hline
\end{tabular}

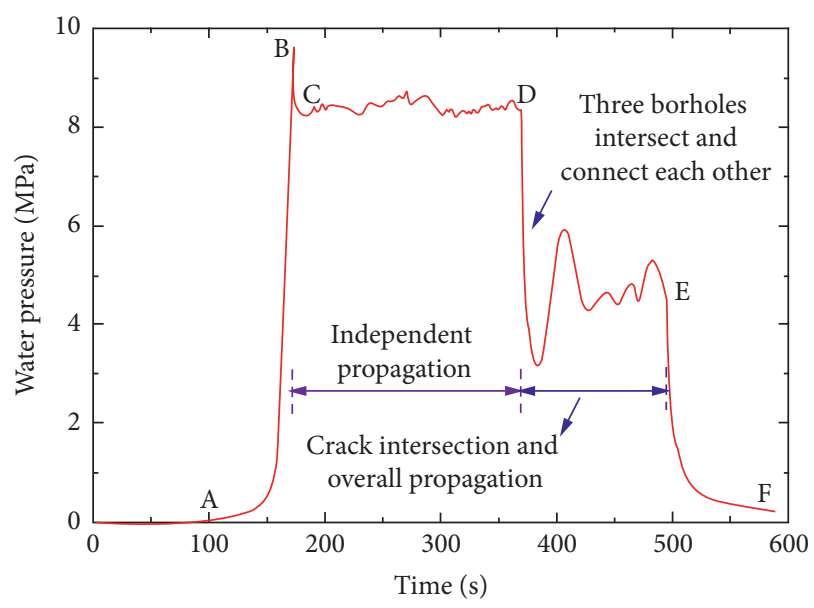

Figure 4: Water pressure curve.

$$
\varphi(s, m)=\frac{m}{s_{0}}\left(\frac{s}{s_{0}}\right)^{m-1} \exp \left[-\left(\frac{s}{s_{0}}\right)^{m}\right]
$$



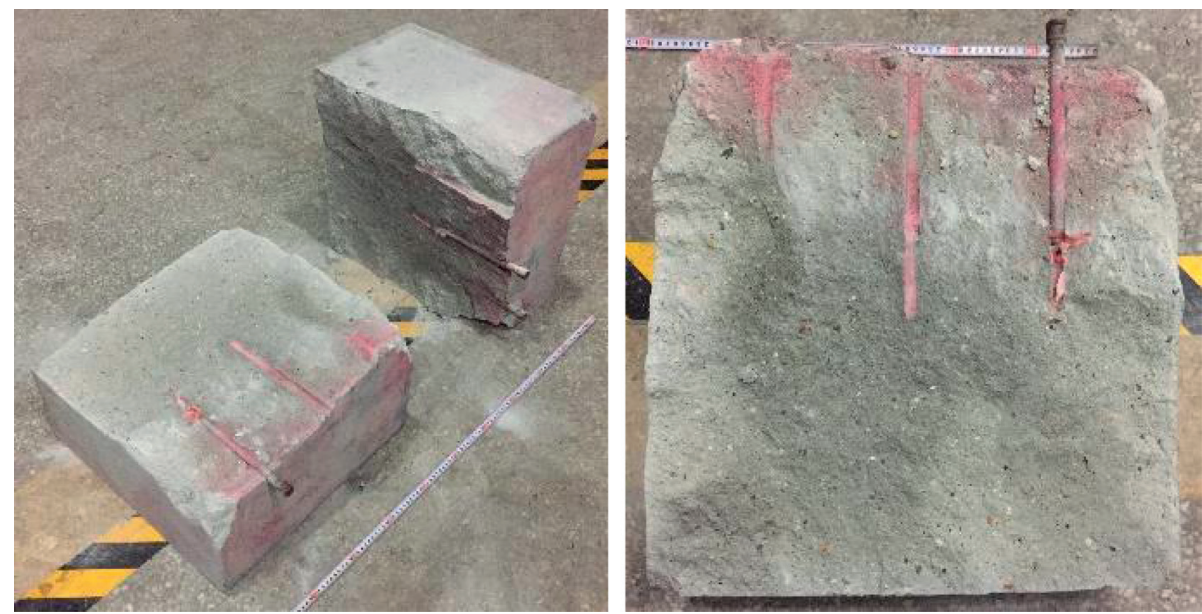

FIGURE 5: Overall morphology of the directional fracture surface.

where $s$ is the macroscopic magnitude of the property, $s_{0}$ is the scale parameter, and $m$ is the homogeneity.

The seepage-stress coupling process in a saturated rock mass can be explained by Biot's consolidation theory [29], RFPA2D-Flow extended Biot's consolidation theory by considering the influence of stress on permeability, through which its basic governing equations were formed:

\subsubsection{Balance Equation.}

$$
\frac{\partial \sigma_{i j}}{\partial x_{i j}}+\rho X_{j}=(i, j=1,2,3)
$$

where $\sigma_{i j}$ is the stress and $X_{j}$ is the body force in the $j$ direction.

\subsubsection{Geometrical Equation.}

$$
\varepsilon_{i j}=\frac{1}{2}\left(u_{i j}+u_{j i}\right) \cdot \varepsilon_{v}=\varepsilon_{11}+\varepsilon_{22}+\varepsilon_{33},
$$

where $\varepsilon_{i j}$ is the strain and $u_{i}$ is the displacement in the $i$ direction.

\subsubsection{Constitutive Equation.}

$$
\sigma_{i j}^{\prime}=\sigma_{i j}-\alpha p \delta_{i j}=\lambda \delta_{i j} \varepsilon_{v}+2 G \varepsilon_{i j},
$$

where $\alpha$ is the coefficient of pore-fluid pressure, $p$ is the pore pressure, $\delta_{i j}$ is the Kronecker constant, $\lambda$ is the Lame coefficient, and $\lambda$ is the shear modulus.

\subsubsection{Seepage Equation.}

$$
k \nabla^{2} p=\frac{1}{Q} \frac{\partial p}{\partial t}-\alpha \frac{\partial \varepsilon_{v}}{\partial t}
$$

where $k$ is the coefficient of permeability and $Q$ is Biot's constant.

\subsubsection{Coupling Equation.}

$$
k(\sigma, p)=k_{0} \exp \left[-\beta\left(\frac{\sigma_{i i} / 3-p}{H}\right)\right],
$$

where $k_{0}$ is the initial coefficient of permeability and $\beta$ is material constant.

Equations (2) (5) are based on Biot's theory of consolidation [30]. Equation (6) represents the influence of stress on permeability, which is achieved by assuming that both permeability and stress follow a negative exponential function.

3.2. The Design of Numerical Model. The numerical model is a cubic rock sample with a cross section of $1000 \mathrm{~mm} \times 1000 \mathrm{~mm}$. A two-dimensional model was established for the sample section, and the model was divided into $500 \times 500$ units by using the plane strain method. The program of numerical simulation is shown in Table 2 and Figure 6. The modified Mohr-Coulomb strength criterion is taken as the failure criterion of rock, where the tension fractures of rocks are taken into consideration. The parameter selection is important for the numerical model. Many studies have been carried out by using a neural network model to predict the mechanical parameters of rock, such as unconfined compressive strength, Young's modulus, and shear strength [31-37]. The spacing and diameter of the boreholes are designed according to the field construction parameters. Five boreholes with a spacing of $141 \mathrm{~mm}$ and a diameter of $18 \mathrm{~mm}$ are drilled to perform the hydraulic fracturing synchronously, and each fractured borehole is equal in water pressure. The angle between the boreholes layout direction and the maximum principal stress direction is $15^{\circ}$. The water pressure of boreholes is loaded step by step from $0 \mathrm{MPa}$ at an increment of $0.3 \mathrm{MPa}$, which simulates the process of hydraulic fracturing.

\section{Numerical Results and Analysis}

4.1. Evolution Process of Pore Pressure. Pore pressure plays an important role during hydraulic fracturing [38]. The contour variation of pore pressure in the process of directional 
TABLE 2: Numerical simulation parameters.

\begin{tabular}{lc}
\hline Rock mass & Parameter \\
\hline The uniaxial compressive strength of rock mass & $20 \mathrm{MPa}$ \\
Elastic modulus & $8000 \mathrm{MPa}$ \\
Internal friction angle & $30^{\circ}$ \\
Porosity & 0.10 \\
Infiltration coefficient & $0.01 \mathrm{~m} / \mathrm{d}$ \\
Ratio of tension and compression & 10 \\
Maximal coefficient of tensile strain & 1.50 \\
The initial value of water-injection pressure & 0 \\
Homogeneity & 1000 \\
Poisson's ratio & 0.25 \\
Coupled coefficient & 0.20 \\
The coefficient of pore pressure & 0.30 \\
Residual strength & $0.10 \%$ \\
The maximal coefficient of compressive strain & 200 \\
The increment of water pressure & $0.30 \mathrm{MPa}$ \\
\hline
\end{tabular}

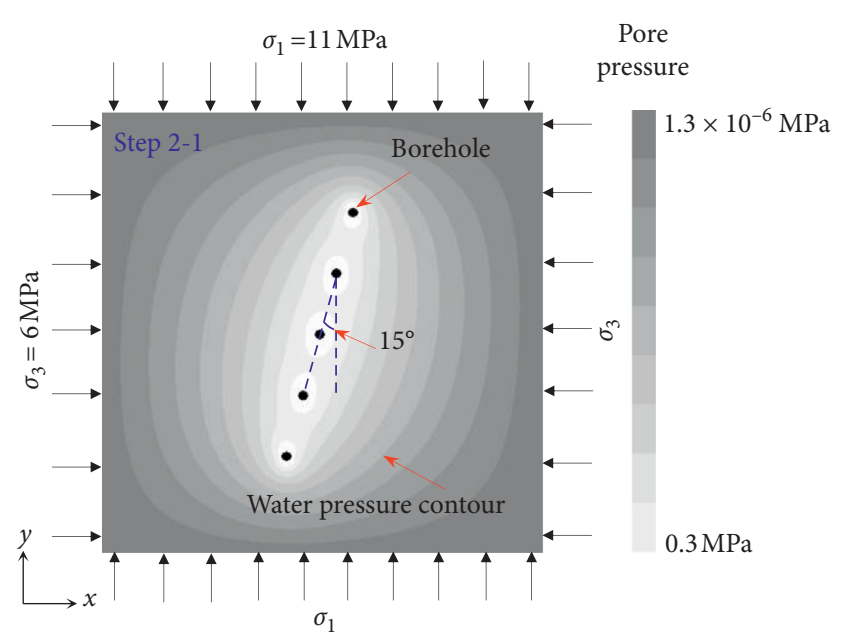

Figure 6: Numerical simulation model.

hydraulic fracturing controlled by dense linear multiboreholes is shown in Figure 7. As water pressure grows, the pressurized water infiltrates into the surrounding rocks of boreholes, which produce pore pressure and its gradient. The distribution of pore pressure builds an oval region of infiltration whose macro axis is the ligature of these boreholes. The axial ratio becomes smaller as the distance from the axes of the boreholes increases. It means that the infiltration coefficients along the direction of boreholes layout are relatively small, which leads to the heavy attenuation of water pressure and large gradient of pore pressure. On the contrary, the infiltration coefficients whose direction is perpendicular to the direction of boreholes layout experience the opposite variation compared with the case above, which leads to slight attenuation of water pressure and a small gradient of pore pressure (Figure 6, Step 2-1). The existence of pore pressure contributes to the prior crack initiation of the borehole walls along the direction of the boreholes layout. In the central area of the boreholes layout, there is an oval region with high pore pressure around every hole. Due to the superimposing effect of pore pressure between dense linear multiboreholes, the long axis of the region is along the direction of boreholes layout. Meanwhile, every region stands alone and does not connect (Figure 6, Step 2-1). When the water pressure goes up to $9.9 \mathrm{MPa}$ (Figure 7, Step 34-1), cracks initiation begins. In this case, the infiltration coefficient along the boreholes layout grows. The high-pressure regions of three middle-positioned boreholes are connected (Figure 8, Step 34-1). When the water pressure continues to rise at $10.8 \mathrm{MPa}$, hydraulic cracks further propagate, and the highest pressure regions are connected (Figure 7, Step 37-2), which results in a connected region of peak pore pressure. As the water pressure reaches $11.2 \mathrm{MPa}$, the hydraulic cracks within boreholes gradually propagate closer and tend to propagate in the direction of the boreholes layout (Figure 7, Step 38-3). Finally, a connected fracturing plane formed along the direction of the boreholes layout (Figure 7, Step 38-6).

4.2. Evolution Process of Poroelastic Stress. Due to the fluidstructure coupling, the pore pressure changes will also induce poroelastic stress change [39]. The contour of horizontal poroelastic stress in the process of hydraulic fracturing is shown in Figure 9. As the pressurized water injects the multiboreholes simultaneously, poroelastic stress concentration regions occur around every borehole. Some regions parallel to the direction of boreholes layout, while the others perpendicular to it. The poroelastic stress concentration regions are connected between boreholes. The poroelastic stress around the middle boreholes is larger than that of the outside two boreholes. Besides, the poroelastic stress grows with the decrease of its distance from boreholes (Figure 10). After the crack initiation along with the direction of boreholes layout, the stress drops from both sides of fractures, which presents an elliptical contour of poroelastic stress. The drop speed of poroelastic stress goes up as the distance from the boreholes layout decreases. With the cracks propagating towards each other, the distance between cracks decreases. The augment of poroelastic stress superposition leads to the poroelastic stress at the tips of cracks increase. The superposing of poroelastic stress fields at the tips of cracks contribute to the connection of fractures during the propagation towards each other, which finally results in a directional fracturing plane along the direction of boreholes layout.

4.3. The Role of Controlling Directional Fracturing. Directional hydraulic fracturing controlled by dense linear multi-boreholes is achieved by controlling the spacing and size of the boreholes to make stresses superimposed between boreholes. The stress superposing causes the stress concentration zone to appear in the direction of the boreholes layout, where the broken occurs preferentially. The role of controlling directional fracturing includes the superimposing of poroelastic stress and pore pressure, and the hydraulic-mechanics coupling effect.

4.3.1. Superimposing of Poroelastic Stress. The rock mass is in equilibrium with stress before hydraulic fracturing, 

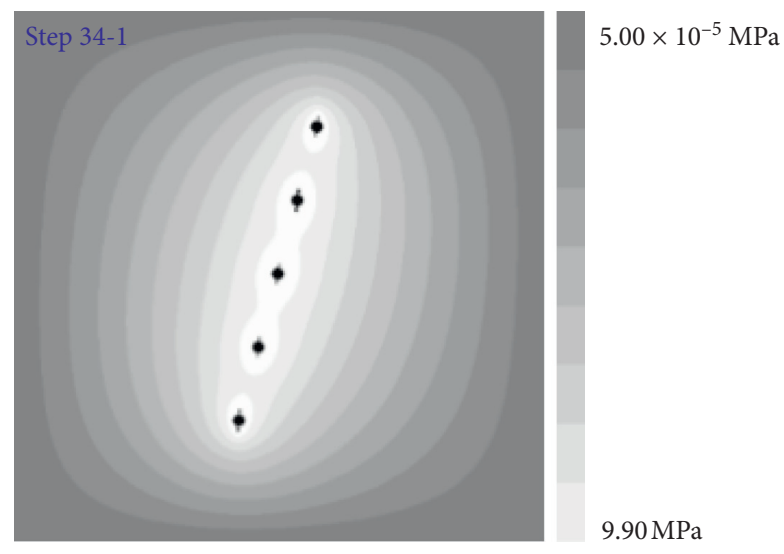

(a)

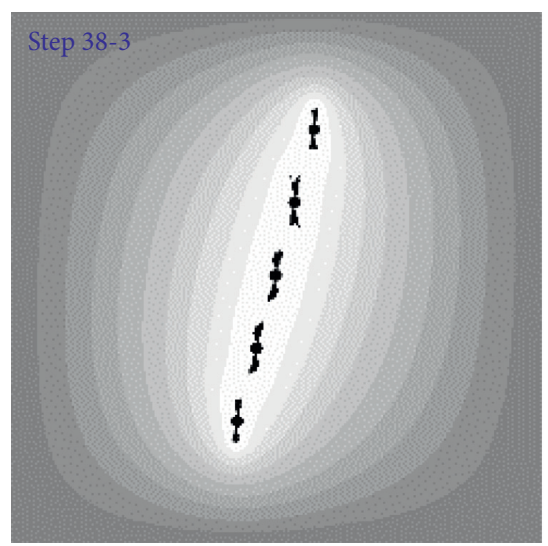

(c)

$7.42 \times 10^{-5} \mathrm{MPa}$
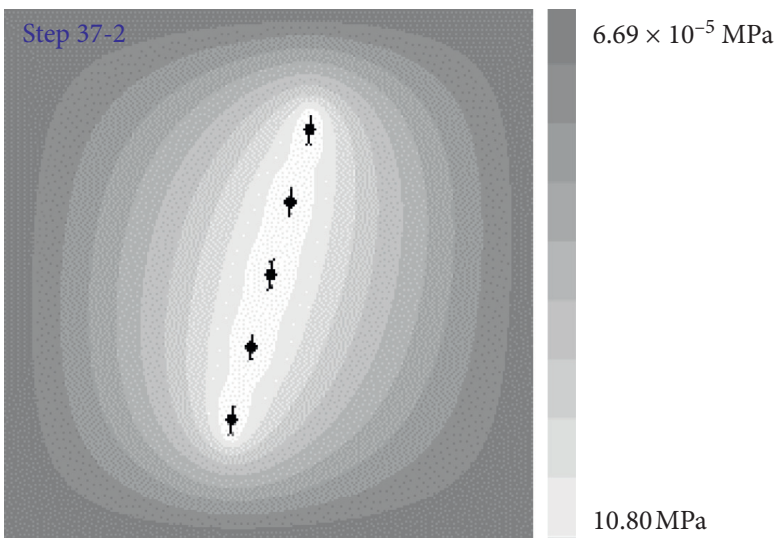

(b)

11.20 MPa
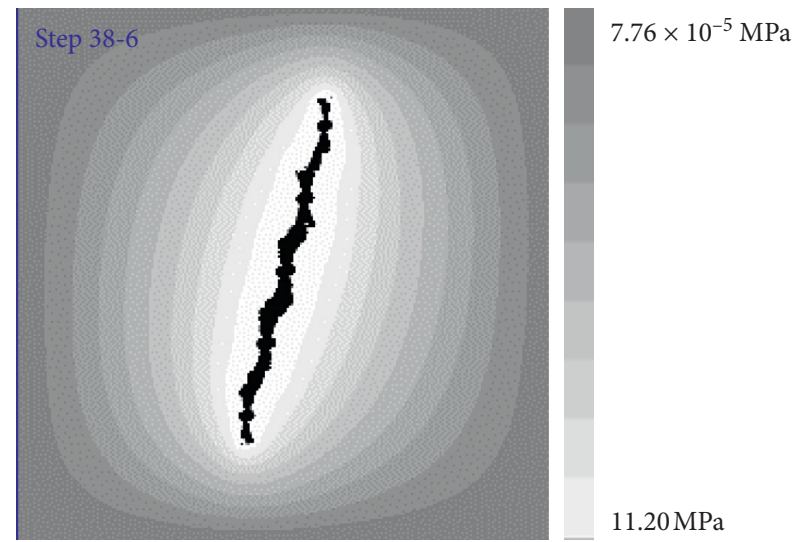

(d)

FIGURE 7: The variation of water pressure contour during hydraulic fracturing.

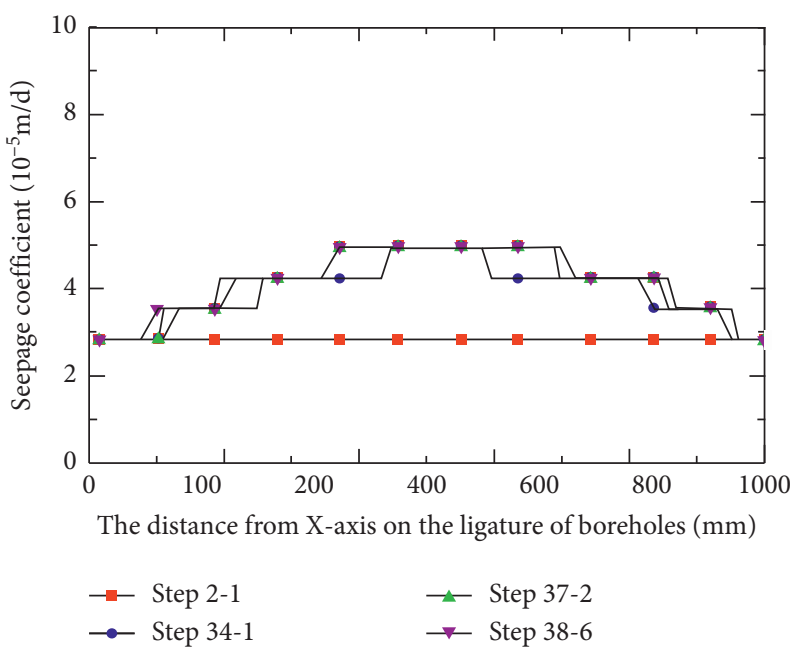

(a)

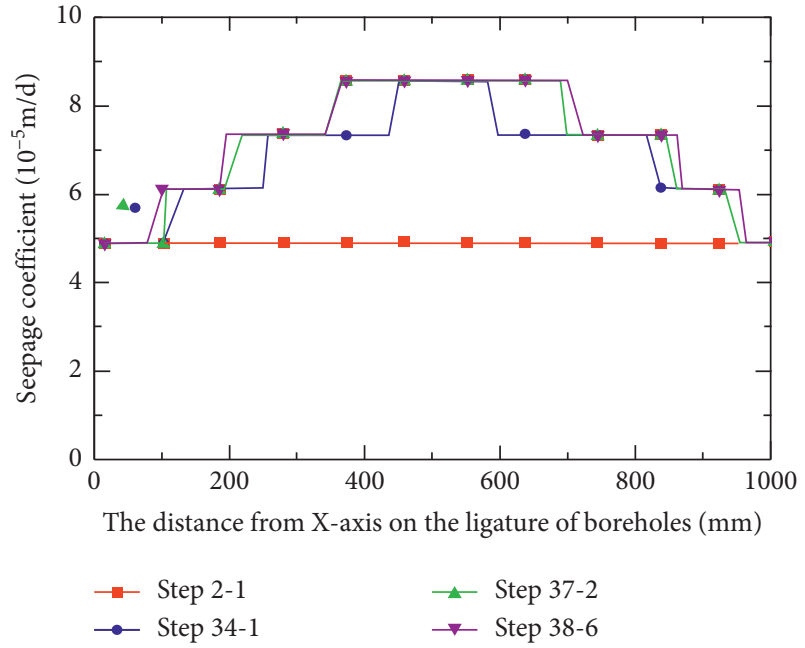

(b)

FIgURE 8: The seepage coefficient variation between boreholes during hydraulic fracturing. (a) Along the direction of borehole layout. (b) Perpendicular to the direction of borehole layout.

borehole drilling can change the stress distribution inside the rock mass, and an area of stress concentration will occur around the borehole. Besides, the borehole will be squeezed by high-pressure water when hydraulic fracturing, which increases the area of stress concentration around the borehole. 


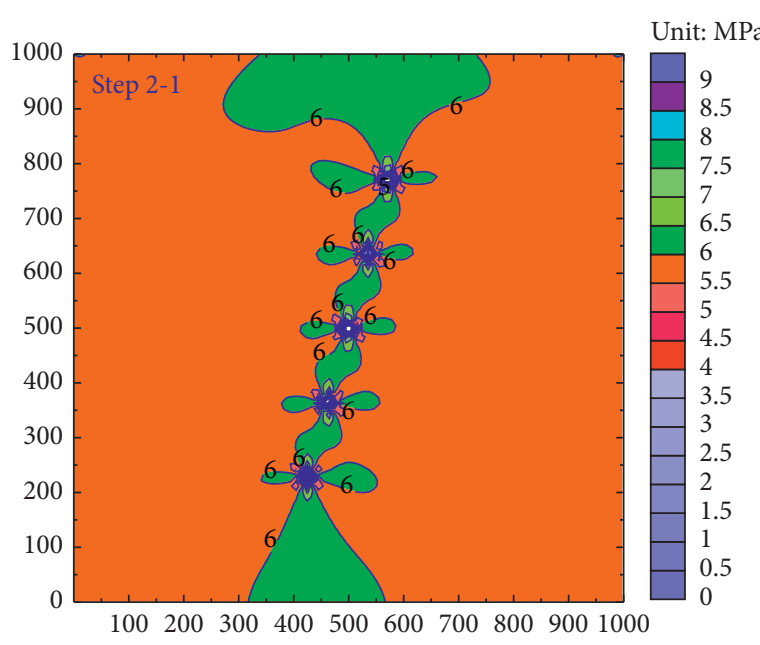

(a)

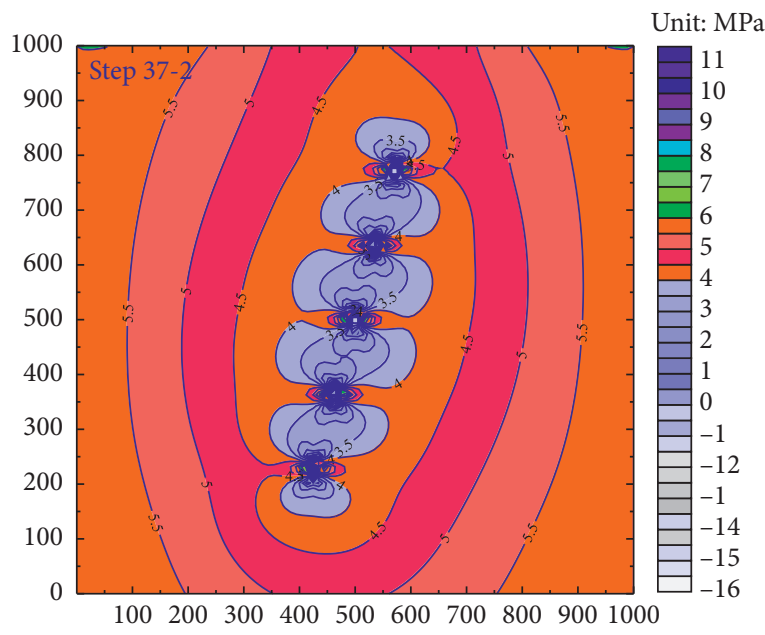

(c)

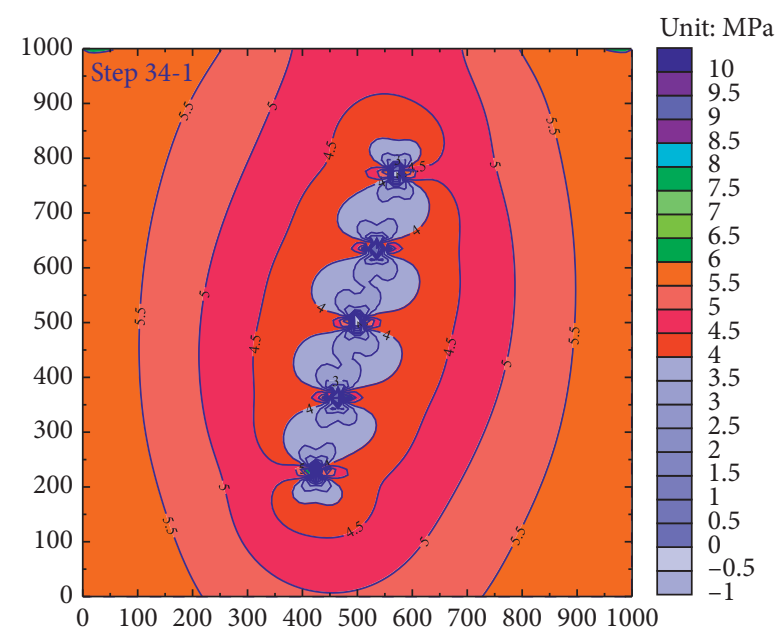

(b)

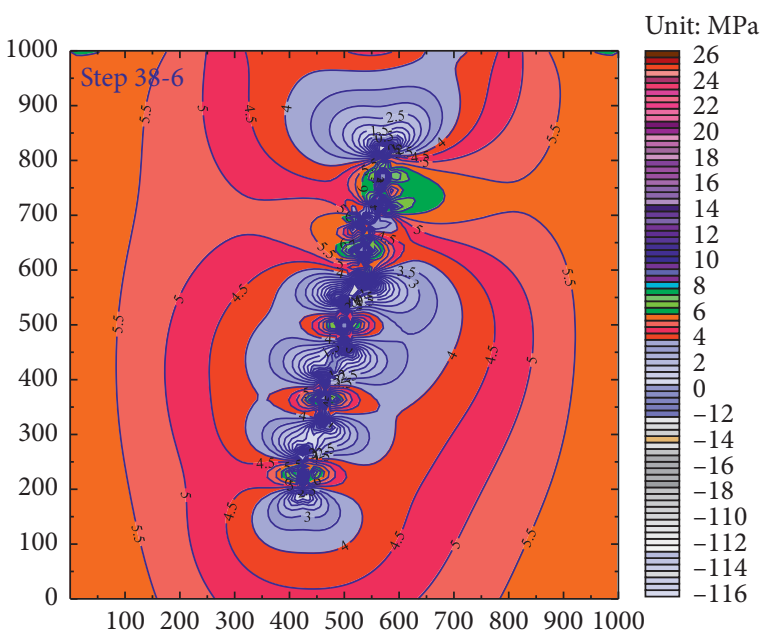

(d)

FIgURE 9: The variation of horizontal poroelastic stress contour during hydraulic fracturing.

The boreholes spacing of dense linear multiboreholes hydraulic fracturing must be smaller than the stress concentration range around boreholes, which keep the adjacent borehole within the stress concentration zone of the borehole. The poroelastic stress concentration zone of adjacent holes will affect each other and superimposed. Finally, a connected poroelastic stress concentration zone between the boreholes is formed. Poroelastic stress gradient will occur between the poroelastic stress concentration zone and the in situ stress zone, which will control the fracture initiation and propagation. The poroelastic stress gradient direction (tangential tensile stress direction) is perpendicular to the direction of the boreholes layout. Therefore, the initiation and propagation direction of hydraulic fractures will be along the direction of the boreholes layout.

4.3.2. Superimposing of Pore Pressure. Rock is a porous medium. Pressurized water can penetrate the rock around the borehole to form pore water pressure during hydraulic

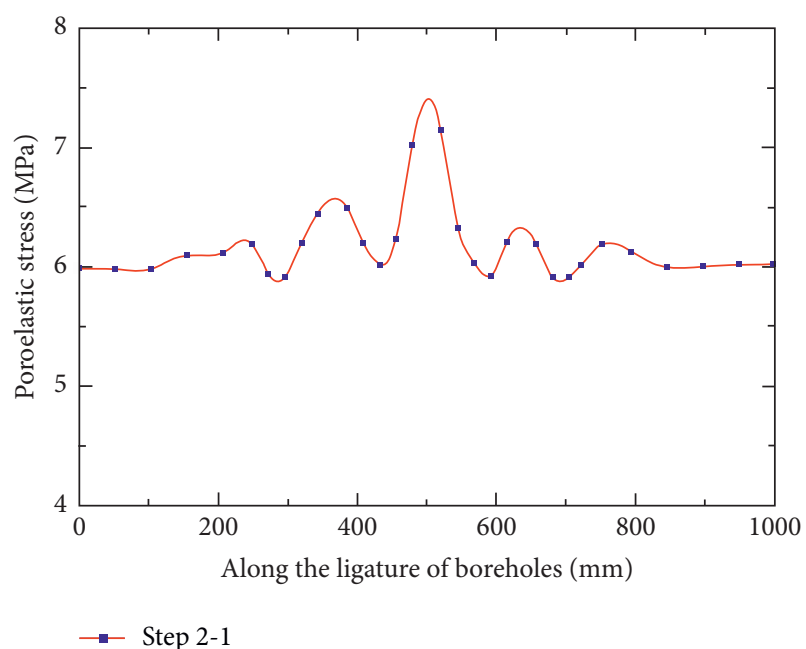

FIGURE 10: The horizontal poroelastic stress distribution along with the boreholes layout before crack initiation. 
fracturing. An area of pore pressure increase will also form around the borehole.

The layout of dense linear multiboreholes keeps each borehole within the pore pressure increase zone of its adjacent borehole. The pore pressure increase zone of adjacent boreholes will affect each other and superimposed. Finally, a connected pore pressure increase zone between the boreholes is formed. Pore pressure gradient will occur between the pore pressure concentration zone and the initial pore pressure zone. The pore pressure gradient direction is also perpendicular to the direction of boreholes layout, which will also induce the initiation and propagation direction of hydraulic fractures along the direction of boreholes layout.

4.3.3. Coupling Effect of Hydraulic-Mechanics. The coupling effect of hydraulic-mechanics between multiboreholes also plays an important role in directional hydraulic fracturing controlled by dense linear multiboreholes. The superposing of poroelastic stress causes the pore structure changes and affects the distribution of pore pressure. Meanwhile, the superposition of pore pressure also causes pore structure changes and affects the distribution of poroelastic stress.

\section{Conclusions}

This study presents the dynamic directional initiation and propagation process of hydraulic fractures between dense linear multi-boreholes through numerical simulation and physical experiment. The dynamic evolution of pore pressure and poroelastic stress during fracturing was also analyzed. The primary conclusions are as follows:

(1) The water pressure curve during the physical model experiment reflected the fractures propagation, intersection, and connection process between boreholes. A directional fracturing plane was formed along the direction of the boreholes layout, and the surface of the fracturing plane is relatively flat.

(2) The initiation and propagation direction of the hydraulic fractures in each borehole are consistent and all along the direction of boreholes layout, which is the guarantee for forming a single flat directional fracturing plane.

(3) Directional fracturing of dense linear multiholes hydraulic fracturing is achieved by controlling the spacing and size of the boreholes to make stresses between boreholes superimposed. The initiation and propagation direction of hydraulic fractures between boreholes can be controlled along the direction of boreholes layout by the superimposing of poroelastic stress and pore pressure, and hydraulic-mechanics coupling effect.

(4) The poroelastic stress concentration zone and pore pressure increase zone appears between holes in the direction of the boreholes layout during directional hydraulic fracturing. The pore pressure distribution is generally an elliptical seepage water pressure zone with the long axis along the direction of the boreholes layout. After the hydraulic fractures are initiated along the direction of boreholes layout, the poroelastic stress on both sides of the direction of boreholes layout decreases.

(5) The future work will focus on the physics model experiment to analyze the influence of principal stress difference, injection rate, borehole aperture, and spacing using real rock samples.

\section{Data Availability}

The data used in the study will be available on request.

\section{Conflicts of Interest}

The authors declare no conflicts of interest.

\section{Acknowledgments}

The authors express their gratitude to the National Natural Science Foundation of China. This research was funded by the National Natural Science Foundation of China (nos. 51774272 and 52004269).

\section{References}

[1] M. C. He, W. F. Cao, and R. L. Shan, "New blasting technology_bilateral cumulative tensile explosion," Chinese Journal of Rock Mechanics and Engineering, vol. 22, pp. 2047-2051, 2003.

[2] H. He, L. Dou, J. Fan, T. Du, and X. Sun, "Deep-hole directional fracturing of thick hard roof for rockburst prevention," Tunnelling and Underground Space Technology, vol. 32, pp. 34-43, 2012.

[3] H. J. Wang, F. L. Huang, and Q. M. Zhang, "Mechanics effect analysis and parameters study on borehole directional fracture blasting," Journal of Coal Science and Engineering, vol. 28, pp. 399-402, 2003.

[4] B.-X. Huang, B. Yu, F. Feng, Z. Li, Y.-Z. Wang, and J.-R. Liu, "Field investigation into directional hydraulic fracturing for hard roof in Tashan coal mine," Rock Mechanics and Rock Engineering, vol. 19, no. 2, pp. 153-159, 2013.

[5] T. Guo, B. Liu, Z. Qu, D. Gong, and L. Xin, "Study on initiation mechanisms of hydraulic fracture guided by vertical multi-radial boreholes," Rock Mechanics and Rock Engineering, vol. 50, no. 7, pp. 1767-1785, 2017.

[6] H. Zhu, J. Deng, X. Jin, L. Hu, and B. Luo, "Hydraulic fracture initiation and propagation from wellbore with oriented perforation," Rock Mechanics and Rock Engineering, vol. 48, no. 2, pp. 585-601, 2015.

[7] R. G. Ketterij and C. J. Pater, "Impact of perforations on hydraulic fracture tortuosity," SPE Production and Facilities, vol. 14, pp. 131-138, 1999.

[8] L. A. Behrmann and J. L. Elbel, "Effect of perforations on fracture initiation," Journal of Petroleum Technology, vol. 43, no. 5, pp. 608-615, 1991.

[9] G. Q. Zhang, M. Chen, and Y. B. Zhao, "Study on initiation and propagation mechanism of fractures in oriented perforation of new wells," Acta Petrolei Sinica, vol. 29, pp. 116-119, 2008.

[10] M. Chen, H. Jiang, G. Q. Zhang, and Y. Jin, “The experimental investigation of fracture propagation behavior and fracture geometry in hydraulic fracturing through oriented 
perforations," Petroleum Science and Technology, vol. 28, no. 13, pp. 1297-1306, 2010.

[11] C. A. Wright, R. A. Conant, D. W. Stewart, and P. M. Byerly, "Reorientation of propped refracture treatments," in Proceedings of the Paper SPE 28078 presented at the 1994 SPE/ ISRM Rock Mechanics in Petroleum Engineering Conference, Delft, Netherland, August 1994.

[12] C. A. Wright, "Reorientation of propped refracture treatments in the lost hills field," in Proceedings of the 1994 SPE Western Regional Meeting, Long Beach, CA, USA, March 1994.

[13] L. Weijers and C. J. Pater, "Fracture reorientation in model tests," in Proceedings of the 1992 Formation Damage Control Symposium, Lafayette, LA, USA, February 2002.

[14] Y. M. Lekontsev and P. V. Sazhin, "Application of the directional hydraulic fracturing at Berezovskaya mine," Journal of Mining Science, vol. 44, no. 3, pp. 253-258, 2008.

[15] J. Q. Deng, C. Lin, Q. Yang, Y. R. Liu, Z. F. Tao, and H. F. Duan, "Investigation of directional hydraulic fracturing based on true tri-axial experiment and finite element modeling," Computers and Geotechnics, vol. 75, pp. 28-47, 2016.

[16] Y. Z. Wang, "Directed initial fracturing condition of preslotted drilling hydraulic fracturing in rock," Master Dissertation, China University of Mining and Technology, Xuzhao, China, 2014.

[17] B. X. Huang and Y. Z. Wang, "Field investigation on crack propagation of directional hydraulic fracturing in hard roof," Journal of Coal Science and Engineering (China), vol. 40, pp. 2002-2008, 2015.

[18] B. X. Huang, S. L. Chen, and X. L. Zhao, "Hydraulic fracturing stress transfer methods to control the strong strata behaviours in gob-side gateroads of longwall mines," Arabian Journal of Geosciences, vol. 10, p. 236, 2017.

[19] B. X. Huang, Research on theory and application of hydraulic fracture weakening for coal-rock mass, Ph.D. Dissertation, China University of Mining and Technology, Xuzhao, China, 2009.

[20] Y. Cheng, Y. Lu, Z. Ge, L. Cheng, J. Zheng, and W. Zhang, "Experimental study on crack propagation control and mechanism analysis of directional hydraulic fracturing," Fuel, vol. 218, pp. 316-324, 2018.

[21] F. Yan, B. Lin, C. Zhu et al., "A novel ECBM extraction technology based on the integration of hydraulic slotting and hydraulic fracturing," Journal of Natural Gas Science and Engineering, vol. 22, pp. 571-579, 2015.

[22] M. K. Rahman and A. H. Joarder, "Investigating productioninduced stress change at fracture tips: implications for a novel hydraulic fracturing technique," Journal of Petroleum Science and Engineering, vol. 51, no. 3-4, pp. 185-196, 2006.

[23] X. Zhao, B. Huang, and Z. Wang, "Experimental investigation on the basic law of directional hydraulic fracturing controlled by dense linear multi-hole drilling," Rock Mechanics and Rock Engineering, vol. 51, no. 6, pp. 1739-1754, 2018.

[24] B. Huang, Y. Wang, and S. Cao, "Cavability control by hydraulic fracturing for top coal caving in hard thick coal seams," International Journal of Rock Mechanics and Mining Sciences, vol. 74, pp. 45-57, 2015.

[25] C. A. Tang, L. G. Tham, P. K. K. Lee, T. H. Yang, and L. C. Li, "Coupled analysis of flow, stress and damage (FSD) in rock failure," International Journal of Rock Mechanics and Mining Sciences, vol. 39, no. 4, pp. 477-489, 2002.

[26] T. H. Yang, L. G. Tham, C. A. Tang, Z. Z. Liang, and Y. Tsui, "Influence of heterogeneity of mechanical properties on hydraulic fracturing in permeable rocks," Rock Mechanics and Rock Engineering, vol. 37, no. 4, pp. 251-275, 2004.
[27] W. C. Zhu and C. A. Tang, "Micromechanical model for simulating the fracture process of rock," Rock Mechanics and Rock Engineering, vol. 37, no. 1, pp. 25-56, 2004.

[28] H. Q. Zhang, Y. N. He, C. A. Tang, B. Ahmad, and L. J. Han, "Application of an improved flow-stress-damage model to the criticality assessment of water inrush in a mine: a case study," Rock Mechanics and Rock Engineering, vol. 42, no. 6, pp. 911-930, 2008.

[29] L. Li, Q. Meng, S. Wan, G. Li, and C. Tang, "A numerical investigation of the hydraulic fracturing behaviour of conglomerate in glutenite formation," Acta Geotechnica, vol. 8, no. 6, pp. 597-618, 2013.

[30] M. A. Biot, "General theory of three-dimensional consolidation," Journal of Applied Physics, vol. 12, no. 2, pp. 155-164, 1941.

[31] Y. Sun, J. Zhang, G. Li, Y. Wang, J. Sun, and C. Jiang, "Optimized neural network using beetle antennae search for predicting the unconfined compressive strength of jet grouting coalcretes," International Journal for Numerical and Analytical Methods in Geomechanics, vol. 43, no. 4, pp. 801813, 2019.

[32] Y. Sun, J. Zhang, G. Li et al., "Determination of Young's modulus of jet grouted coalcretes using an intelligent model," Engineering Geology, vol. 252, pp. 43-53, 2019.

[33] Y. T. Sun, G. C. Li, N. Zhang, Q. L. Chang, J. H. Xu, and J. F. Zhang, "Development of ensemble learning models to evaluate the strength of coal-grout materials," International Journal of Mining Science and Technology, 2020, In prees.

[34] J. Zhang, D. Li, and Y. Wang, "Predicting tunnel squeezing using a hybrid classifier ensemble with incomplete data," Bulletin of Engineering Geology and the Environment, vol. 79, no. 6, pp. 3245-3256, 2020.

[35] J. Zhang, Y. Wang, Y. Sun, and G. Li, "Strength of ensemble learning in multiclass classification of rockburst intensity," International Journal for Numerical and Analytical Methods in Geomechanics, vol. 44, no. 13, pp. 1833-1853, 2020.

[36] Y. T. Sun, G. C. Li, H. Basarir, A. Karrech, and M. R. Azadi, "Laboratory evaluation of shear strength properties for cement-based grouted coal mass," Arabian Journal of Geosciences, vol. 12, no. 22, p. 690, 2019.

[37] J. F. Zhang, Y. T. Sun, G. C. Li, Y. H. Wang, J. B. Sun, and J. X. Li, "Machine-learning-assisted shear strength prediction of reinforced concrete beams with and without stirrups," Engineering with Computers, 2020.

[38] Y. Ji, W. A. M. Wanniarachchi, and W. Wu, "Effect of fluid pressure heterogeneity on injection-induced fracture activation," Computers and Geotechnics, vol. 123, p. 103589, 2020.

[39] L. Wang, G. Kwiatek, E. Rybacki, A. Bonnelye, M. Bohnhoff, and G. Dresen, "Laboratory study on fluid-induced fault slip behavior: the role of fluid pressurization rate," Geophysical Research Letters, vol. 47, no. 6, Article ID e2019GL086627, 2020. 